\title{
The co-grazing of cattle and sheep under rotational and continuous grazing
}

\author{
SM Kitessa, AM Nicol \\ Animal and Veterinary Sciences Group, PO Box 84, Lincoln University, New Zealand
}

In their review of mixed grazing, Nolan and Connolly (1977, Herbage Abstracts, 47, 367374) showed considerable variation in the response of cattle and sheep to mixed grazing. They identified a number of factors as potential sources of this variation but did not consider grazing system. This experiment reports the growth rate of cattle and sheep co-grazed under rotational or continuous grazing.

Nine yearling heifers (188 kg liveweight) and 27 ewe hoggets (45 kg liveweight) were continuously co-grazed for 19 weeks on an irrigated perennial ryegrass - white clover pasture (2.95 ha) maintained at a sward surface height (SSH) of $5 \mathrm{~cm}$ by adding or removing additional animals in a fixed ratio (1: 1 W 0.75 cattle : sheep). Similar groups of animals were rotationally co-grazed on perennial ryegrass-white clover pasture (15.9 $\mathrm{cm}$ pre-grazing $\mathrm{SSH}$ ) where they received a new area of pasture daily and also had access to the area grazed over the previous 2 days. The size of the new area provided daily was such that the weekly liveweight change of the rotationally grazed sheep was equal to that of the continuously grazed group. The mean post-grazing $\mathrm{SSH}$ on the rotational grazing treatment was $5.6 \mathrm{~cm}$. SSH was recorded daily ( 60 observations / treatment).
The daily liveweight gain (DLWG, regression of liveweight $(\mathrm{kg})$ on time (d)) of the treatment groups is shown in the table below. As determined by the protocol of the experiment, there was no significant difference in the daily liveweight gain of sheep under continuous and rotational grazing. In contrast, cattle rotationally co-grazed with sheep grew $33 \%$ faster $(1.027 \mathrm{~kg} /$ day) than continuously cograzed cattle $(0.767 \mathrm{~kg} / \mathrm{d})$. Consequently, the ratio of cattle : sheep DLWG/ha increased from $1.8: 1$ under continuous grazing to $2.4: 1$ with rotational grazing.

The lower DLWG of continuously co-grazed cattle may have been a response to the lower mean SSH under continuous $(5.0 \mathrm{~cm})$ than rotational $(10.7 \mathrm{~cm})$ grazing, or the inability of cattle to compete well with sheep where there is a small, continual renewal of the pasture resource (continuous grazing) in contrast to a large, periodic renewal under rotational grazing.

This experiment shows that the results of mixed grazing experiments do depend on the grazing system applied. When high cattle liveweight gain/head is required from mixed grazing, rotational co-grazing should be adopted in preference to continuous co-grazing.

\section{Grazing System}

Daily liveweight gain

Sheep $(\mathrm{g} / \mathrm{d})$

Cattle $(\mathrm{kg} / \mathrm{d})$
Continuous

$$
147 \pm 7
$$

$0.767 \pm 0.063$
Rotational

$$
139 \pm 7
$$$$
1.027 \pm 0.063
$$

Significance

NS

$P<0.01$ 